\title{
Experienced General Dental Practitioners as Clinical Teachers: A Qualitative Study of Their Experience over the First Three Years as Novice Clinical Teachers in an Outreach Setting
}

David R Radford ${ }^{1,2}$, Paul Hellyer ${ }^{1,2}$, Kim A Jones ${ }^{1,2}$ and Nigel Meakin ${ }^{1,2}$

${ }^{1}$ University Portsmouth Dental Academy, United Kingdom

${ }^{2}$ King's College London Dental Institute, United Kingdom

\begin{abstract}
Introduction: Outreach training has become an important element of the undergraduate curriculum. Part time general dental practitioners (GDPs) are the professionals of choice to deliver this educational experience yet little work has been undertaken into this transition to clinical teaching.

Methods: Using a qualitative approach, a thematic analysis was undertaken of clinical teaching accounts written by three novice teachers. The setting was a large inner city outreach centre of the University of Portsmouth, teaching final year dental students from King's College London, in an integrated team care environment with dental hygiene therapy and dental nurse students.

Results: Three major themes were identified. These were: What is clinical dental education? Me as a "clinical teacher" and Specific teaching issues.

Discussion: The analysis of the written accounts brought together many issues that have been addressed separately in the literature. However, the themes highlighted the complexity of dental education and the different environment of the teaching clinic from general practice. Some of these themes in future could be discussed in small peer group seminars to facilitate an easier transition from experienced GDP to clinical teacher.
\end{abstract}

Conclusion: Within the limitations of this study the themes demonstrate the breadth and complexity of clinical education which is experienced in both dental schools and in outreach education.

Keywords: General dental practitioners; Novice clinical teachers; Outreach

\section{Introduction}

Increasingly, with the widespread education of dental students in outreach centres in the UK, experienced dental practitioners are becoming clinical teachers, teaching a full range of clinical dentistry in a primary care setting [1-5]. In the UK, dental practitioners have taught in dental schools on a part time basis since the inception of formal Dental University Education but very much within the structure established in the dental schools by senior full time academic teachers.

Analysis of outreach teaching initiatives normally focuses on the outcomes of the students' experiences and due to the success of these initiatives it is considered a positive learning environment. For example The Maurice Wohl General Dental Practice Centre of King's College London was one of the earlier outreach facilities opened in 1987 and regular reports on student's satisfaction are published [4]. Positive outcomes often are measured against generic Outcome Objectives that have been used to define outreach education. These include:-

Personal Development - 'to encourage students' progress towards professional working and increase their confidence in the clinical environment'.

Professional Responsibility - 'to encourage students to appreciate the ethical responsibility of dental professionals for oral health and optimal care for the whole community'.

Practice Environment - 'to encourage students to appreciate the responsibilities and requirements of the practice environment within the primary care setting'.

Further Development of Clinical Skills - 'to consolidate awareness and develop students' skills in the provision of comprehensive oral care for a range of patient groups including the hard to reach'. (Modified from Smith et al. [6] at the inception of the Academy in 2010)
Some work has been published on the development of the teaching team and how they relate to the mother dental school [3] and the need to train teachers in outreach settings [1]. However, there appears to be a dearth of evidence of the personal journeys that experienced practitioners go through to become clinical teachers in order to be able to optimise the student teacher interaction for the benefit of patient outcome. The research question formulated was therefore- Are there common experiences, teaching philosophies and practices that have been adopted by a group of highly experienced general dental practitioners who are new to clinical teaching of dental undergraduates?

\section{Methods}

The context of the research environment was at the recently established University of Portsmouth Dental Academy (UPDA). The University of Portsmouth established the School for Professionals Complimentary to Dentistry in 2004, providing a three year BSc Honours programme education for a cohort of 24 dental hygiene therapy students. Subsequently, collaboration was proposed between the University of Portsmouth and King's College London Dental Institute to provide an outreach experience for $50 \%$ of final year dental

*Corresponding author: David R Radford, Faculty of Science, University of Portsmouth Dental Academy, United Kingdom, Tel: 02392843498; E-mail: david.radford@kcl.ac.uk

Received: June 11, 2014; Accepted: September 02, 2014; Published: September 09, 2014

Citation: Radford DR, Hellyer P, Jones KA, Meakin N (2014) Experienced General Dental Practitioners as Clinical Teachers: A Qualitative Study of their Experience over the First Three Years as Novice Clinical Teachers in an Outreach Setting. J Interdiscipl Med Dent Sci 2: 147. doi: 10.4172/2376-032X.1000147

Copyright: @ 2014 Radford DR, et al. This is an open-access article distributed under the terms of the Creative Commons Attribution License, which permits unrestricted use, distribution, and reproduction in any medium, provided the original author and source are credited. 
Citation: Radford DR, Hellyer P, Jones KA, Meakin N (2014) Experienced General Dental Practitioners as Clinical Teachers: A Qualitative Study of their Experience over the First Three Years as Novice Clinical Teachers in an Outreach Setting. J Interdiscipl Med Dent Sci 2: 147. doi: $10.4172 / 2376-032 X .1000147$

Page 2 of 7

students in a primary care setting, alongside dental hygiene therapy colleagues in training [5]. The aspiration was that this would provide education to students training to be dental care professionals, to practice and interact together both on and off the clinic, creating interprofessional education and communities of practice that mimic real life environments [7].

\section{Subject material}

Three clinical teachers were identified who were undertaking their Graduate Certificate in Academic Practice (GCAP) offered by King's Learning Institute, King's College London and who gave consent for their personal narratives to be analysed to investigate the research question. As part of their initial teacher education (GCAP), in addition to formal educational workshop sessions and teaching observations, they had to complete a 7,000 word reflective autoethnographical account of their teaching practice to date. These accounts were analysed using grounded theory to identify common themes of their experiences as novice clinical teachers. The reports were read in detail by one person outside the GCAP process (D) and after several readings, themes and sub themes that were common or particularly prominent were indentified. The transcription of these themes and sub themes were then scrutinised by all three of the participants who also then reread all the reports to confirm the themes and identify any further sub themes. This was subsequently discussed in a round table discussion of all four authors as per accepted protocols for this type of research [8]. Names and gender of the participants have been anonymised.

To understand the context of where the participants/authors started their journey as dental educators mini bios of the 4 authors are given in Table 1.

The three clinical teachers $(\mathrm{A}, \mathrm{B}, \mathrm{C})$ provide just over $50 \%$ of the clinical teaching to the dental students in the Academy. Although in autoethnography type research bias is understood to be intrinsic, for the purposes of this paper the bias of the individuals is fully elucidated. Author D has bias from his full time career in academic dentistry and clinical teaching. Further there is bias as he line manages the three participants and has taken a role in their development as clinical teachers. Last, all four participants work at the same institution and regularly work together on the same clinic. They therefore bring bias as they are confident in the quality of the experience that they and their fellow clinical teachers are providing for their student colleagues.

\section{Results}

The thematic analysis identified three major themes

1) What is clinical dental education? (what does it involve?)

2) Me as a "clinical teacher"

3) Specific teaching issues and coping strategies.

\section{What is Clinical Dental education? (what does it involve?)}

The subthemes identified included: The complexity of dental education, Skills and knowledge of a new dentist, Interacting with agencies (internal and external) and Outreach experience and environment.

Complexity of dental education: The complexity of dental education was recognised by the novice clinical teachers with the theme being a recurrent feature of the three accounts.

Within the more complex environment of $5^{\text {th }}$ year outreach

\begin{tabular}{|c|c|}
\hline Author & Biography \\
\hline \multirow{7}{*}{ A } & Qualified in 1971 \\
\hline & Spent 5 years as an associate in 3 general practices \\
\hline & Became an expense sharing principal from 1977-2007 \\
\hline & Awarded MSc in Gerodontology in 1989 \\
\hline & Taught CPD courses for GDPs 1989-1996 \\
\hline & Joined the William Beatty Dental Service at SPCD from 2007-2010 \\
\hline & Appointed part-time clinical teacher 2010 at UPDA and KCLDI. \\
\hline \multirow{7}{*}{ B } & Qualified in 1981 \\
\hline & Spent 2 years as an associate \\
\hline & Became a principal in 1984 \\
\hline & Practice inspector for FPC for 16 years \\
\hline & Held various LDC roles \\
\hline & Appointed to SPCD as a part-time clinical teacher, 2009 \\
\hline & Appointed to UPDA as a part-time clinical teacher, 2010 \\
\hline \multirow{9}{*}{ C } & Qualified in 1985 \\
\hline & Appointed to a junior hospital post for 6 months \\
\hline & Joined RADC for 3 years \\
\hline & Spent 4 years in associate positions in the UK and Hong Kong \\
\hline & Rejoined RADC for 8 years \\
\hline & Spent 10 years as an associate in the UK \\
\hline & Appointed part-time postgraduate dental tutor 2008 \\
\hline & Appointed to UPDA as a part-time clinical teacher 2010 \\
\hline & Appointed part-time adviser to Postgraduate Dental Deanery 2011 \\
\hline \multirow{5}{*}{ D } & Qualified in 1981 \\
\hline & Appointed to various junior hospital posts till 1987 \\
\hline & Appointed full time lecturer at UMDS 1987 \\
\hline & Appointed Senior lecturer/Honorary consultant KCLDI 1997 \\
\hline & Appointed Director of Clinical Studies at UPDA 2009 \\
\hline \multirow{7}{*}{ Glossary } & FPC - Family Practitioner Committee \\
\hline & KCLDI - King's College London Dental Institute \\
\hline & LDC - Local Dental Committee \\
\hline & RADC - Royal Army Dental Corps \\
\hline & UMDS - United Medical and Dental Hospitals of Guy's and St Thomas' \\
\hline & SPCD - School of Professionals Complementary to Dentistry \\
\hline & UPDA - University of Portsmouth Dental Academy \\
\hline
\end{tabular}

Table 1: Author biographies.

teaching, students apparently bring with them at least some 'chains' of understanding. My role must be to attempt to bring together these chains into a network of understanding. A

I realised that the role of the clinical teacher is complex. On reflection, I now understand that it is more than just supervision alone but about encouraging and guiding the student to reflect on their own practice. $\mathrm{B}$

Skills and knowledge of a new dentist: The clinical teachers were aware of various models that place skills and knowledge into context through their formal didactic teaching and were curious in trying to explore where their students fitted into the proposed models.

Certainly on this scale [9], my students were 'consciously incompetent' in that they were aware of their shortcomings. To be 'consciously incompetent' they have begun the journey to become reflective practitioners. My role is to assist them, within the context of this outreach experience, to help them seek their own answers - to become independent reflective practitioners. A

Students learn best when we respect their existing knowledge, give them responsibility and then allow them to learn at their own pace. C

I can relate to the "3-P Model of Learning" [10], because my "world of learning" is individual to my aspirations and interests. I lean towards a teaching style to promote deep 'learner centredness' and although I 
Citation: Radford DR, Hellyer P, Jones KA, Meakin N (2014) Experienced General Dental Practitioners as Clinical Teachers: A Qualitative Study of their Experience over the First Three Years as Novice Clinical Teachers in an Outreach Setting. J Interdiscipl Med Dent Sci 2: 147. doi: $10.4172 / 2376-032 X .1000147$

Page 3 of 7

understand 'Surface' and 'Strategic' approaches to study, they do not sit comfortably with me. I also accept that every teacher and/or individual student will have their own preferred approach to study, and the continuous challenge is to push each other to achieve quality learning outcomes such as deep learning, insight, autonomous learning and the ability to become critically reflective. $\mathrm{C}$

\section{Interacting with agencies}

Interaction with internal agencies: The novice teachers recognised the roles of both internal and external agencies on their teaching input.

In order for me to understand my role in order to facilitate this, I found it necessary to investigate the curriculum so that I would know what to teach and when to teach it. For me, I see the curriculum as a road map that is to be explored with the student. B

To be an efficient teacher/adviser in higher education I must know and understand my role in each organisation. $\mathrm{C}$

One novice teacher possibly due to their higher clinical work load as well as educational input into all the professionals in training at the Academy discussed the concept of the spiral curriculum [11]. A spiral curriculum assists students as they progress from knowledge-based activity to application in the clinical environment. They stated 'A spiral curriculum is one in which there is an iterative revisiting of topics, subjects or themes throughout the course. A spiral curriculum is not simply the repetition of a topic taught. It requires also the deepening of it, with each successive encounter building on the previous one' [11].

Therefore, I have learnt to ensure that repeated clinical encounters are built upon to gain experience and there is a requirement for deeper learning through the articulation of the more complex outcomes. I am in a fortunate position of having a work-load of eight clinical sessions per week and being a team lead - this allows me to 'know' the individual abilities of the students and their previous experiences so that I am able to build on these 'repeated episodes'. B

Interaction with External agencies: Role of The General Dental Council (UK)

They all quite naturally made comment of the major role that the General Dental Council (GDC) has on their role as teachers particularly the interaction of the links of the domains of learning [12].

Professionalism: I see that one of my roles as a clinical teacher is to model what I perceive to be good, professional practice. This might be in the way that I communicate with patients, in the manner in which I interact with students, in the priorities of the subject matter that I teach, in the way that I relate with team members and colleagues. A

Communication: I believe, for instance, that demonstrating good communication skills with patients is one of the most important features of what I do, particularly in the teaching of denture provision. This is the 'Heart' of dental education. For instance, I will try to stand in front of the patient, make eye contact, introduce myself, shake hands and never speak from behind a mask. A

Committing to lifelong learning and developing as a reflective practitioner: The GDC, in their 'Standards for Dental Professionals' [13] state that as dentists we should "Continuously review your knowledge, skills and professional performance. Reflect on them, and identify and understand your limits as well as your strengths". One clinical teacher described their role to embed into their teaching $a$ commitment to lifelong learning, possibly due to their other role in the local postgraduate deanery.

A Clinical Teacher's role is to enable the medical/dental undergraduate to achieve their primary qualification but this is only the first step in their education which will last throughout their practising life. C

The earlier students learn to reflect on their learning, to try to identify what they don't know and to deeper understand what they do know, the better professionals they will be. I believe my 'use of silence' and questions facilitate this skill. A

The outreach experience and environment: Much has been written about the successful introduction of outreach teaching and as the teachers were working in this environment it featured heavily in their reports of their experience as novice teachers. Elkind et al. [2] concluded that 'outreach is a different and more demanding context for teaching than the dental hospital, characterised by isolation, management responsibility, pressure, a steep learning curve and stress. The desirable characteristics of outreach teachers are those which enable them to cope in this environment, together with a studentcentred teaching style and the appropriate knowledge'.

For me, it has been an exciting challenge to try teach the students the realities of a primary care environment and to apply the teaching they have received in the previous 4 years to the holistic care of patients. A

Clinical practice for students allows the transition of theory to practice. Many of the learning outcomes are covered earlier in the programme but their application demands the need for a deeper approach to learning to enable the scaffolding of knowledge in relation to complexity and significance. B

Our challenge, as their teachers, is to give them autonomy on the live student clinics, particularly as they get closer to qualification, but to know when to intervene without adversely impacting on student confidence and/or allowing patient safety and treatment outcomes to be compromised. C

Me as a "clinical teacher": Naturally they reflected on themselves as clinical teachers and this section is divided into the subthemes of - Me teaching "professional practice", Me teaching "clinical skills", "what I do day in, day out" and understanding oneself as a "Clinical teacher".

Me Teaching "Professional practice": Professional practice was reflected through all three accounts but in terms of "teaching professional practice" rather than as practicing dentists which would have been the theme of the participants when they were working as dental practitioners rather than GDP clinical teachers.

It is a core professional belief and personal philosophy as a teacher that practising clinicians should help prepare and pass on experience to future practitioners. B

I am a very enthusiastic teacher who tries to lead by example. I put myself in the student's shoes and think about the qualities I admired in Clinical Teachers when I was an undergraduate [dental] student. I always strive to give a good individual performance and hope that this contributes to maximising the performance of others. C

Me Teaching "Clinical Skills": Surprisingly only one clinical teacher discussed in any detail this aspect of their role. This possibly is as their main role in developing final year students to make the transition into foundation training and independant practice and as 
Citation: Radford DR, Hellyer P, Jones KA, Meakin N (2014) Experienced General Dental Practitioners as Clinical Teachers: A Qualitative Study of their Experience over the First Three Years as Novice Clinical Teachers in an Outreach Setting. J Interdiscipl Med Dent Sci 2: 147. doi: $10.4172 / 2376-032 X .1000147$

Page 4 of 7

such are allowing students to develop autonomy as opposed to teaching fundamental clinical skills as is necessary in early years at dental school. Even this one teacher did not major on this role, as competence in a range of technical skills is just one factor in this complex educational involvement.

I need to be able to demonstrate good clinical skills. ---"I should be able to show them what to do and how to do it. I need to be able to identify where they are going wrong, and identify solutions for these."--and I need to be able to help the students to see the end result - not just 'how' but 'why'. A

What I do day in and day out: Again naturally the novice teachers' accounts majored on how their personal philosophy of teaching impacts on what they do every day when undertaking clinical supervision.

In this new learning environment - not dissimilar to my working life in general practice - my aim is to distil my experience and expertise and transmit that to students. A

The student presentation is often straightforward for me because I am fully aware of the patient history and their progress through their care plan. I must be mindful, however, to allow the student to make a full and un-interrupted presentation. There is also an opportunity for an advanced student to provide an in-depth and focussed high level approach to their presentation with detailed and informed questioning from me. B

Any teacher needs to understand what makes their students 'tick' in order to meet their needs most effectively. It is of paramount importance that a Clinical Teacher is student-focused from the very beginning of the relationship because our 'Subject', when teaching takes place on the live student clinic, is the patient. I try to be an effective listener with the aim of finding out how much the student knows about a topic, what their basic assumptions are, i.e. what drives them, and what they want to learn more about. C

\section{Understanding oneself as a "Clinical teacher"}

Oneself: Although only one of the participants discussed this aspect, as this was a recurrent and powerful theme that developed through their portfolio, it is included:

I would define my learning ability as that of the 'Reflective Observer' and, instead of trying to fight against my learning style, I now 'go with the flow' and try to operate within understood parameters. This has, as a consequence, enabled me to be far more empathetic and effective when assisting students to learn within their individual comfort zones and/or gently push them into their 'Zone of proximal development' [14]. C

As Clinical Teachers, with our own commitment to Lifelong Learning, feedback must be a reciprocal process because we too, continuously learn from our students' experiences, either via the students themselves, their patients, carers and/or other members of the multi-disciplinary team. C

Developing as a "clinical teacher": The aspect of their role and where they positioned themselves was reflected in their portfolios often to five types of clinical teacher [15].

In addition, the descriptor - having 'knowledge of dentistry and wide clinical experience' - describes my career so far. A

When I first started teaching on the Hygiene, Therapy Student clinic, I was unsure of the process of clinical teaching and my role. The students have developing under-pinning knowledge and varying degrees of experience. I presumed I would help them learn and gain experience and that my clinical teaching would need to focus on communication, clinical reasoning, information management and operative skills. B

Satisfaction and the future: All three of the novice clinical teachers expressed their deep satisfaction with their new role and this is in line with the pilot findings of part-time practitioner teachers at King's College London [16].

What I do now have is a far greater understanding of the processes of teaching and learning. What I also know is that now overlaid over my 'networks of understanding' of dentistry, I now have the beginning and it is only a beginning - of another network, that of the educational process itself. My task for the future is to continue to read the literature which will help me develop this further network of understanding, in order then to be a 'good teacher', in keeping with the values of the Higher Education Academy UK (HEA). A

Overall, feedback from the Hygiene Therapy and Dental Students has been supportive of my teaching and I was delighted to receive recognition from King's in 2011. As my confidence and learning has developed I feel I have been able to participate in progressive teaching that has enabled my personal philosophy as a teacher to be fulfilled. B

Reflection about my journey so far has made me realise that to fulfil my own career potential, I had to find a niche of like-minded people who share the same values as me. I consider myself extremely lucky to have found those people in both of the organisations that I now work for - the University of Portsmouth Dental Academy and regional Deanery. I am now in the right jobs for me and it is exciting that every day provides new challenges as each organisation evolves to survive and prosper in these financially challenging times. C

Specific teaching issues and coping strategies: Interwoven through the three accounts the clinical teacher used examples and cited frustrations of clinical teaching. They recognised the dynamic of the three parties in clinical education, the importance of feedback and how to deliver it and finally the juggling of time and numbers of students.

The Three Way Dynamic: The novice teachers were also aware of the three way dynamic with a critical balance between the Subject, the Teacher and the Learner.

I must 'observe proceedings' in an understated way without undermining the student in front of their patient but, at the same time, I can never allow patient safety to be compromised. A

There is not only interaction between the Teacher and the Learner, i.e. the student, there is interaction with a live Subject, i.e. the patient. C

I can really relate to this model because my goal as a Clinical Teacher is to set up the relationship between the patient and the student and then stand back, but still have 'eyes in the back of my head'. C

Giving Feedback: All three of the clinical teachers appear to have thought carefully on how to use and give effective feedback. This is gratifying as the results of surveys' including the National Student survey UK, students on the whole tend to give low scores for this aspect of their education [16].

When giving feedback on clinic, I encourage them to think by asking further questions of them. Also, by being open and approachable, I encourage them to ask questions of me, either on clinic or by email. A

Students expect feedback from their supervising tutor. Feedback is also available from a variety of other sources including staff nurses and patients. We encourage students to discuss their feedback at the practice 
Citation: Radford DR, Hellyer P, Jones KA, Meakin N (2014) Experienced General Dental Practitioners as Clinical Teachers: A Qualitative Study of their Experience over the First Three Years as Novice Clinical Teachers in an Outreach Setting. J Interdiscipl Med Dent Sci 2: 147. doi: $10.4172 / 2376-032 X .1000147$

Page 5 of 7

team meetings in order to share trends in the way we work and influence the way in which the team behaves. Additionally, we have found the use of patient feedback to be powerful in reinforcing practice and catalytic in identifying new ways to practice. $\mathrm{B}$

I find immediate constructive feedback is an invaluable tool in developing a student's skills; and will always try to identify any positive aspects of a performance but have to be honest about how the skill can be improved. C

Time and numbers: As all clinical teachers they recognised the pressure of managing a large number of students often working at the approach to their limit of experience.

I am in a fortunate position of having a work-load of eight clinical sessions per week and being a team lead - this allows me to 'know' the individual abilities of the students and their previous experiences so that I am able to build on these 'repeated episodes'. B

Students learn best when we respect their existing knowledge, give them responsibility and then allow them to learn at their own pace. However, with a minimum of eighty [final year] dental students, in addition to fifty [Level 5/Level 6] hygiene/therapy students engaged in the delivery of patient care, we cannot develop effective [learning] relationships with every learner and this may result in an 'unconsciously incompetent' student having too much autonomy. C

\section{Discussion}

All three participants discussed in detail in their personal narratives how they perceived dental education from their experience of teaching in an outreach environment for three years. The approach to bring these accounts together is widely accepted by exponents of autoethnography [8]. By inviting the participants to read each other's narratives along with the initial thematic analysis that had been indentified, the research is then grounded by the analysis in the participants' understanding as well as that of the primary researcher [8]. Further, through knowledge gained in their didactic sessions, the participants tried to link their experience to various educational theories. Such in-depth analysis produces very rich data and thus small numbers of participants are routinly recruited to such studies. The complexity of dental education was well recognised and the participants discussed this in terms of the component parts which have been collated as 8 key factors Table 2 [17].

The component part or skills itemised in Table 2 will have become second nature to experienced GDPs (they have become unconsciously competent) [9] but a different skill set is needed to unpack them and apply them to patient and student management in a busy outreach teaching clinic. These skills have been extensively explored and have been well defined by the GDC as well as other organisations including Association for Dental Education in Europe [18]. In the most simple terms, three different skill sets needed by graduating dental students have been identified and are summarised as 'head', 'heart' and 'hands'

\begin{tabular}{|l|l|}
\hline 1 & Remembering a large amount of factual information \\
\hline 2 & Understanding complex mechanisms \\
\hline 3 & Competence in a range of technical skills \\
\hline 4 & Understanding and use of the scientific method \\
\hline 5 & $\begin{array}{l}\text { Developing professionalism, socially responsible attitudes and ethical } \\
\text { practice }\end{array}$ \\
\hline 6 & Deploying interpersonal skills for working with colleagues and patients \\
\hline 7 & Developing sophisticated problem-solving and diagnostic reasoning skills \\
\hline 8 & Personal skills, including self-evaluation and reflective practice \\
\hline
\end{tabular}

Table 2: Factors to be considered in the education of dentists.

\begin{tabular}{|l|l|l|}
\hline Domain & Type of skill & Shorthand \\
\hline Psychomotor & $\begin{array}{l}\text { Technical skill and clinical knowledge; } \\
\text { competence at procedures }\end{array}$ & Hands (do) \\
\hline Affective & $\begin{array}{l}\text { Understand, motivate and empathise with } \\
\text { patients }\end{array}$ & Heart (feel) \\
\hline Cognitive & $\begin{array}{l}\text { Critical, clinical reasoning; rational decision } \\
\text { making; knowledge of facts }\end{array}$ & Head (think) \\
\hline
\end{tabular}

Table 3: Link between Bloom's domain's of learning and skills needed for dentistry.

Table 3 [19]. 'Head' implies knowledge and understanding and the ability to reason. 'Heart' implies the ability to empathise and motivate patients, whilst 'Hands' is the technical skill required to carry out dental treatment and it has been suggested that the categories 'head', 'heart' and 'hands' link into Bloom's domains of learning [19].

Skills progression has been classified into 5 stages:- Novice $\rightarrow$ Advanced beginner $\rightarrow$ Competent $\rightarrow$ Proficient $\rightarrow$ Expert [20]. In another skills progression hierarchy, developed for skills training in a business environment. Gordon [9] suggested that students pass from:Unconsciously incompetent $\rightarrow$ consciously incompetent $\rightarrow$ consciously competent $\rightarrow$ unconsciously competent. One participant leant heavily on the theory to underpin their academic practice.

---my students were 'consciously incompetent' in that they were aware of their shortcomings. To be 'consciously incompetent' they have begun the journey to become reflective practitioners. A

The three participants were aware of the need to inculcate a deeper learning and referred to Bloom's Taxonomy [21] which covers six levels of cognitive ability from knowledge, comprehension, application, analysis and synthesis to evaluation. The ability to achieve these levels will increase with the increasing competence of the student. This has been described as increasing competence as the development of 'Professional Authenticity' from someone who 'Knows' to 'Knows how' to 'Shows how' to someone who 'Does' [22]. Some students may strategically 'tick off' these competencies to become technically capable practitioners. Others may 'cross-link' knowledge structures to become 'understanding' practitioners capable of holistic care and to later develop expertise. Kinchin et al. [23] described this through concept mapping as 'chains of practice and networks of understanding, the interaction and transformation between defining the term expertise'. In a subsequent paper Kinchin et al. [24] applied this to the clinical setting - 'the typical structure of a clinical procedure would be a chain of practice that would be communicated to the student. The student's competence would be assessed through his/her ability to reproduce the chain under varying conditions with various patients. The student's expertise, however, must be assessed through his/her ability to relate the chain of practice to the underlying network of understanding, and explaining how the elements are linked, and how and why the chain of practice should be modified in response to changes of context'.

McMillan [25] has suggested that 'questioning helps students retrieve what they know and apply it appropriately in new contexts' and 'helps students to think about and verbalise their understanding of the relationships between isolated knowledge'. She also suggested that 'clinical teachers should think out loud, as this communicates a general framework for solving the clinical problems'. In some ways, she is verbalising the more complex language of Kinchin et al. [20] in simpler terms - her 'isolated knowledge' is Kinchin's 'chain of practice' - her 'frameworks', 'nets'. Despite this, McMillan described the clinical teacher's underlying knowledge as 'tacit', whereas Kinchin used the links between chains and nets as a way trying to expose the expert's knowledge and experience to investigation and understanding [25] 
Citation: Radford DR, Hellyer P, Jones KA, Meakin N (2014) Experienced General Dental Practitioners as Clinical Teachers: A Qualitative Study of their Experience over the First Three Years as Novice Clinical Teachers in an Outreach Setting. J Interdiscipl Med Dent Sci 2: 147. doi: $10.4172 / 2376-032 X .1000147$

Page 6 of 7

One participant related strongly to the use of questions interspersed with appropriate silence to allow the students to develop their nets of understanding.

\section{I believe my 'use of silence' and questions facilitate this skill. A}

Biggs [10] has identified an approach to study - what he calls a strategic approach - which allows students to be able to choose which approach to learning is appropriate for each circumstance. There is not necessarily a right or wrong way to learn.

However clearly part of my role is to help them achieve a position where they do have a choice of learning techniques. I do this by pointing them to other external sources of information (textbooks, for instance) where they may notice a different or more accessible explanation of the relevant material. C

The participants discussed their development as teachers, often referring to the work of Sweet et al. [15] who recognised five types of clinical teacher (Table 4). From their research the category 'Dental practitioners' see 'their position as one who helps students by example and as role models'. In the context of the GDC guidelines, this is an important part of students' learning.

Certainly it came through strongly that the novice teachers recognised that they had embarked upon a new journey.

What I do now have is a far greater understanding of the processes of teaching and learning. What I also know is that now overlaid over my 'networks of understanding' of dentistry, I now have the beginning and it is only a beginning - of another network, that of the educational process itself. A

As my confidence and learning has developed I feel I have been able to participate in progressive teaching that has enabled my personal philosophy as a teacher to be fulfilled. B

They aspired to the higher levels of the hierarchy [15] of being both an intuitive teacher and gaining teacher training which has to be an important skills progression and recognised by Dental Faculties. As GDPs who teach part of their time, they add considerable richness to the learning experience of our more junior (student) colleagues.

All three participants were highly reflective in their reports and this is obvious in their professional and teaching lives with numerous quotes in the results section demonstrating this important quality in a teacher

"Reflection about my journey so far has made me realise that to fulfil my own career potential, I had to find a niche of like-minded people who share the same values as me". C

They also were well aware of the concept that has been be termed the 'The three way dynamic' for the purpose of thematic analysis. The SubTLe model of learning and teaching [26], makes reference to the balance between the Subject, the Teacher and the Learner by using the analogy of 3 points of a triangle and varying the position of the 3 main components. In the Subject dominant 'Traditional role', the teacher interprets the Subject to the Learner; is the 'servant' of the Subject, but the 'master' of the Learner. Within this concept between teacher, patient and student, the patient is the most vulnerable'. [17]

The identified themes and subthemes are of interest as they are often common to both teaching in dental schools as well as outreach settings and could form the basis of initial teacher education of both full and part time teachers. This may therefore reduce the time that clinical teachers take to "find their feet" in a challenging environment where unlike their normal general practice they are in charge of their every action with regards to delivery of care. The open student clinic can be an intimidating environment and possibly some new clinical tutors may feel isolated. Induction and education in the form of small peer group seminars along the themes identified in this in-depth analysis of the 3 novice teachers' experiences may allow an easier transition from GDP to clinical teacher. The identification and allocation of resources of a senior teacher/lecturer to mentor new clinical teachers may also be beneficial. These initiatives should facilitate increasingly effective outreach clinical education and thus provide our student colleagues with the optimal individual learning experiences that will allow them to reach their full potential.

Although the teacher portfolios were not comprehensive as their teacher roles were restricted primarily to final year dental student education, the teachers did discuss in detail aspects including the teaching and embedding of fundamental clinical skills. Further they did not elaborate on teaching strategies and this would be useful for induction of the novel teacher either as shadowing a more experienced 'expert' teacher or in feedback of development forums such as symposia of clinical teaching hosted by the HEA.

It is clear from their portfolios that teaching clinical dentistry is a highly complex and demanding role. To that end Clinical Deans of Schools and Directors of Teaching need to be mindful of this to ensure that new staff are supported both in terms of a reduced supervisory role and access to high quality clinical teacher educational fora as well as being able to observe other teachers to develop their own style and strengths. Again, although partly aspirational, certainly with the current demands from both students and patients alike, the 'three way dynamic of patient, student and teacher' needs to be supported if dental schools are going to attract and develop the highest quality clinical teachers who are able to give an exceptional experience to the students in terms of their clinical education.

Last, as has been recognised by others, this area is under researched and if we are going to discontinue to expouse the old mantra of the 1980 and 90s of "see one - do one and then teach one", this whole area of the transition from experienced clinical practitioner through to novice teacher to experienced clinical teacher needs to be further explored. Further to that although such concepts discussed in this study with regards to clinical teaching are often anecdotally heard, they have not been formally researched.

\section{Conclusions}

Within the limitations of this study certain themes and subthemes

\begin{tabular}{|l|l|}
\hline Dental practitioners & knowledge of dentistry, wide clinical experience \\
\hline Senior academics & knowledge of dentistry, wide clinical experience, additional subject specificity \\
\hline Intuitive teacher practitioners & knowledge of dentistry, critically appraised clinical experience, intuitive good teaching ability \\
\hline Teacher trained academic & knowledge of dentistry, wide clinical experience, knowledge of processes of education \\
\hline Dental educational developers & knowledge of dentistry, wide clinical experience, knowledge of processes of education, critical appraisal of teaching and systems \\
\hline
\end{tabular}

Table 4: Perceptions of chairside teachers and what they bring to the clinical situation from Sweet et al [14]. 
Citation: Radford DR, Hellyer P, Jones KA, Meakin N (2014) Experienced General Dental Practitioners as Clinical Teachers: A Qualitative Study of their Experience over the First Three Years as Novice Clinical Teachers in an Outreach Setting. J Interdiscipl Med Dent Sci 2: 147. doi: $10.4172 / 2376-032 X .1000147$

were identified. The themes demonstrate the breadth and complexity of clinical education which is experienced both in dental schools and in outreach education.

\section{Acknowledgement}

The authors would like to acknowledge the help of Prof Mark Woolford in the preparation of this paper, and Dr Desha Desia in formal teaching sessions and help in the preparation of clinical teacher portfolios.

\section{References}

1. Eaton KA, de Vries J, Widstrom E, Gait TC, Bedi R, et al. (2006) Schools without walls?' Developments and challenges in dental outreach teaching report of a recent symposium. Eur J Dent Educ 10: 186-191.

2. Elkind A, Watts C, Qualtrough A, Blinkhorn AS, Potter C, et al. (2007) The use of outreach clinics for teaching undergraduate restorative dentistry. $\mathrm{Br}$ Dent $J$ 203: 127-132.

3. Craddock HL (2008) Outreach teaching- the Leeds experience: reflections after one year. Br Dent J 204: 319-324.

4. Davies BR, Leung AN, Dunne SM (2009) Perceptions of a simulated general dental practice facility-reported experience from past students at the Mauice Wohl General Dental Practice Centre 2001-2008. Br Dent J 207: 371-376.

5. Radford DR (2011) A personal perspective, breaking new ground in Portsmouth in integrated dental education and professional care. Higher Education Research Network Journal 2: 67-71.

6. Smith M, Ash P, Gilmour ASM, Austin T, Robinson PG (2011) Outreach training: the special interest group's report. Eur J Dent Educ 15: 85-89.

7. Barr H. Interprofessional education : today, yesterday and tomorrow- Centre for Health Sciences and Practice. LTSN 2000: London.

8. Ellis C, Bochner AP (2000) Authoethnography, personal narrative, reflexivity. In Denzin N,K Lincoln YS (eds) Handbook of qualitative research. ( $2^{\text {nd }} \mathrm{ed}$ ). Thousand Oaks: Sage Publications.

9. http://www.gordontraining.com/free-workplace-articles/learning-a-new-skill-iseasier-said-than-done/.

10. Biggs JB (1989) Approaches to the enhancement of tertiary teaching. Higher Educ Res Devel 8: 7-25.

11. Harden R, Stamper N (1991) What is a spiral curriculum? Med Teach 21: 141-143.
12. http://www.gdcuk.org/Newsandpublications/Publications/Publications/ GDC\%20Learning\%20Outcomes.pdf

13. http://www.gdcuk.org/Newsandpublications/Publications/Publications/ StandardsforDentalProfessionals[1].pdf.

14. http://www.learning-theories.com/vygotskys-social-learning-theory.html.

15. Sweet J, Pugsley L, Wilson J (2008) Stakeholder perceptions of chair side teaching and learning in one UK dental school. Br Dent J 205: 499-503.

16. Davies BR, Leung AN, Dunne SM (2013) Why do general dental practitioners become involved in clinical teaching? A pilot study exploring the views of parttime practitioner teachers, Kings College London. Br Dent J 214: 461-456.

17. Fry H, Ketteridge S, Marshall S. (2009) A handbook for teaching and learning in higher education. ( $2^{\text {nd }}$ edn $)$, Oxford: Routledge.

18. Manogue M, McLoughlin J, Christersson C, Delap E, Lindh C, et al. (2011) Curriculum structure, content, learning and assessment in European undergraduate dental education - update 2010. Eur J Dent Educ 15: 133-141.

19. McHarg J, Kay E (2009) Designing a dental curriculum for the twenty-first century. Br Dent J 207: 493-497.

20. Kinchin I, Cabot L, Hay D (2008) Visualising expertise: towards an authentic pedagogy for higher education. Teach Higher Edu 13: 315-326.

21. Bloom BS (1979) Taxonomy of educational objectives, Handbook 1: The cognitive domain. David McKay: New York.

22. Miller G (1990) The assessment of clinical skills/competence/performance. Acad Med suppl 65: 63-67.

23. Kinchin I, Cabot L, Hay D (2008) Visualising expertise towards an authentic pedagogy for higher. Education. Teach Higher Educ 13: 315-326.

24. Kinchin I, Baysan A, Cabot L (2008) Towards a pedagogy for clinical education beyond individual learning differences. J Fur Higher Educ 32: 373-387.

25. McMillan W (2010) Making the most of teaching at the chairside. Eur J Dent Educ 15: 63-68.

26. Atherton JS (1999) 'Learner, subject and teacher' Doceo; subject teacher learner.
Citation: Radford DR, Hellyer P, Jones KA, Meakin N (2014) Experienced General Dental Practitioners as Clinical Teachers: A Qualitative Study of their Experience over the First Three Years as Novice Clinical Teachers in an Outreach Setting. J Interdiscipl Med Dent Sci 2: 147. doi: 10.4172/2376-032X.1000147
Submit your next manuscript and get advantages of OMICS Group submissions

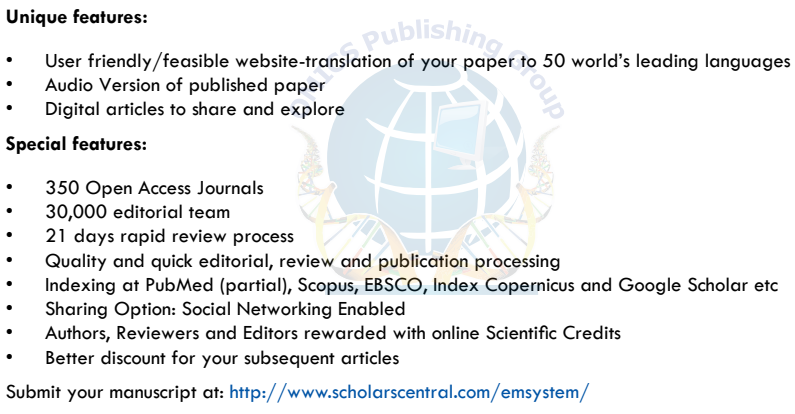

